\title{
Formação profissional em lazer, nos cursos de Educação Física, no Estado de São Paulo
}

\author{
André De Filippis* \\ Nelson Carvalho Marcellino**
}

\begin{abstract}
Resumo: Este trabalho tem como objetivo investigar as relações entre a formação profissional em lazer nos cursos de Educação Física e o mercado de trabalho na área do lazer; se há diferenças na formação do bacharelado e da licenciatura e de que modo os cursos vêm trabalhando a formação profissional para atuação na área. Foram realizadas pesquisas bibliográfica e documental, por análise de conteúdo. Os resultados destacam que o número de disciplinas está aumentando, não se reduzindo à recreação, mas contemplando as relações com outras esferas da vida, historicidade e abrangendo os diferentes conteúdos culturais.
\end{abstract}

Palavras-chave: Formação Profissional. Educação Física. Atividades de Lazer.

\section{INTRODUÇÃO}

O interesse por este tema surgiu pela vivência da separação dos cursos de Educação Física em licenciatura e bacharelado, o que despertou dúvidas quanto ao ensino do lazer nestes dois cursos, agora diferentes.

Outro ponto decisivo na escolha do tema foi a aproximação com a recreação que, por motivos históricos, foi atrelada à educação física, acarretando a ideia de que o profissional dessa área seria o mais apto a trabalhar com lazer. Hoje o lazer é tido como um campo multidisciplinar, que requer a participação de uma equipe de vários profissionais das mais diversas áreas, como Educação Física, Turismo, Hotelaria, Administração, Terapia Ocupacional, entre outras.

\footnotetext{
'Mestre em Educação Física pela Facis-Unimep. E-mail: a_filippis@yahoo.com.br "Livre docente em Educação Física- Estudos do Lazer- pela UNICAMP, Professor do Mestrado em Educação Física, pela UNIMEP, E-mail: marcelin@supernet.com.br
} 
Isayama (2003), ao discutir a atuação do profissional de educação física em relação ao lazer, diz que se faz necessário entendê-lo como um campo de atuação multidisciplinar, que favorece a concretização de propostas interdisciplinares, pois nesse campo é possível verificar-se a atuação de profissionais de diferentes formações, o que enriquece a atuação nessa área. É possível verificar que a atuação, no âmbito do lazer, requer, do profissional uma formação específica, considerando que sua atuação necessita da compreensão de questões gerais sobre a temática. Embora muitos pensem que a esse profissional basta conhecer um vasto repertório de atividades para aplicá-las de modo a entreter os indivíduos que nelas buscam o prazer, preocupando-se apenas em tornar agradável sua participação, necessita de conhecimentos teóricos para efetuar seu trabalho.

Sobre esse aspecto, Leila M. S. M. Pinto (2008, p. 46) apresenta um quadro sobre as práticas educativas pelo e para o lazer no Brasil: em geral, as práticas educativas pelo e para o lazer no Brasil dominantes até a década de 1980 e com grande influência ainda hoje - têm sido marcadas por perspectivas instrumentais e utilitaristas, que dão prioridade aos aspectos técnicos das atividades culturais no lazer, em detrimento da compreensão das relações e mediações humanas nelas vividos. A reversão desse quadro passou a ser uma demanda crescente desde os anos 1990, com o avanço da consciência sobre a importância do lazer como um dos fatores de qualidade de vida, por parte da população e do poder público e privado.

A formação de futuros profissionais e/ou professores de Educação Física é a principal investigação dessa pesquisa. Assim, é importante encontrar uma coerência nas propostas de ensinoaprendizagem durante sua formação sobre os estudos do lazer e suas relações com a atuação profissional.

O lazer tem despertado interesse no ensino, na pesquisa e na extensão, nas instituições de ensino e pesquisa de todo o País, particularmente na área da Educação Física. Mas, isso não se restringe ao âmbito da formação profissional e acadêmica, atingindo, também, o mercado de trabalho da área, que vem sendo anunciado como um 
dos mais promissores do século como campo de intervenção multiprofissional para várias áreas do conhecimento, dentre as quais a Educação Física (WERNECK, 2003).

Ao abordar a necessidade do estabelecimento de diretrizes para uma política de lazer, Requixa (1980) destaca que algumas devem ser consideradas: a ordenação do espaço, a reordenação do tempo e a política de recursos humanos, na qual estão incluídas a política de animação e a formação e qualificação dos quadros para atuação.

Neste sentido, apesar de enfatizar a necessidade de serem trabalhadas todas essas diretrizes, Marcellino (1995) destaca que um dos pilares para a composição de uma política de lazer é a formação de recursos humanos para a atuação, sendo importante seu desenvolvimento em toda a estrutura de animação.

O objetivo é investigar as relações entre a formação profissional em lazer nos cursos de Educação Física e o mercado de trabalho na área do lazer; se há diferenças na formação do bacharelado e da licenciatura e de que modo os cursos vêm trabalhando a formação profissional para atuação na área.

Para atender os objetivos, optamos por realizar uma pesquisa bibliográfica, (SEVERINO, 2002), seguida de uma pesquisa documental (BRUYNE, 1991), por análise de conteúdo (GIL, 2002).

Os cursos de ensino superior de Educação Física foram selecionados por critérios de representatividade e acessibilidade e por estarem localizados no estado de São Paulo, onde o mercado de trabalho do profissional de educação física que atua com lazer está mais desenvolvido. Foram três instituições particulares e três públicas, próximas à cidade de Piracicaba, SP, sede da Unimep, onde a pesquisa se desenvolveu. Estas instituições foram nomeadas da seguinte forma:

*I1 - Instituição particular em cidade de médio porte do interior do estado de São Paulo, com cursos de licenciatura e bacharelado;

*I2 - Instituição particular em cidade sede de região metropolitana do estado de São Paulo, com cursos de licenciatura e 
bacharelado;

*I3 - Instituição estadual em cidade de médio porte do interior do estado de São Paulo com cursos de licenciatura e bacharelado;

*I4 - Instituição estadual em cidade sede de região metropolitana do estado de São Paulo com cursos de licenciatura e bacharelado;

*I5 - Instituição estadual em cidade sede de região metropolitana do estado de São Paulo de grande porte com cursos de licenciatura e bacharelado; e

*I6 - Instituição particular em cidade de grande porte do interior do estado São Paulo com cursos de licenciatura e bacharelado.

Para a coleta dos documentos houve o contato com os coordenadores e/ou diretores dos cursos de Ensino Superior em Educação Física selecionados para o estudo, para os quais foi enviada uma carta de apresentação e a documentação emitida pelo Comitê de Ética da Universidade Metodista de Pairacicaba e solicitada permissão para realização da pesquisa, tendo aprovação de todos os cursos selecionados. O modo de investigação foi o estudo comparativo (BRUYNE, 1991) com o objetivo de melhor analisar as universidades selecionadas.

Foram levantadas sete categorias de análise. São elas: (1) como o lazer é citado nos projetos pedagógicos; (2) disciplinas diretamente vinculadas aos estudos do lazer; (3) vinculação das disciplinas com as outras esferas da vida; (4) vinculação das disciplinas com relação aos conteúdos culturais do lazer; (5) vinculação das disciplinas com os conteúdos físico-esportivos; (6) relação da bibliografia básica utilizada nas ementas das disciplinas relacionadas ao lazer e (7) a relação entre teoria e prática.

Quanto ao lazer, utilizamos o conceito de Marcellino (1990), que o entende como a cultura que pode ser vivenciada em seu sentido mais amplo, em que não se busca outra recompensa além da satisfação provocada pela situação, tendo como traço definidor o caráter desinteressado, respeitados os aspectos tempo e atitude. Além 
disso, os pesquisadores concordam com a caracterização do lazer em seus seis conteúdos, desenvolvidos por Dumazedier, Camargo e, mais tarde, abordados por Marcellino.

Desta forma, há possibilidade de ver o lazer como um campo de atuação rico e amplo para os profissionais de educação física, em que a especificidade desta está nos conteúdos físico-esportivos do lazer.

\section{Análise e discussão}

\subsection{COMO O LAZER É CITADO NOS PROJETOS PEDAGÓGICOS}

Das seis instituições analisadas, apenas uma (I5) não cita o lazer em seu projeto pedagógico. Em todas as outras há menção ao lazer.

Este fato produziu certa inquietação sobre a atuação profissional; todos os profissionais formados em Educação Física, em qualquer instituição de ensino, serão considerados aptos a atuar em qualquer área da educação física, inclusive no lazer, independentemente de ter estudado durante a formação inicial. Por este e outros motivos, defende a inclusão do lazer nos projetos pedagógicos das universidades e faculdades.

A segunda preocupação foi observar como o lazer é citado nos projetos pedagógicos das cinco instituições que o estão mencionado.

Três instituições (I1, I3 e I6) relacionam o lazer ao ensino de projetos de lazer em clubes e espaços públicos. Quatro instituições (I1, I2, I3 e I6) abordam a disciplina com componentes relacionados aos conteúdos do lazer, práticas recreacionais e políticas públicas de esporte e lazer. Quanto à questão do perfil profissional, quatro instituições abordam esta temática (I1, I2, I3 e I4). Sobre o lazer como eixo de conhecimento da Educação Física, o tema aparece em três instituições (I3, I4 e I6). Finalmente, sobre educação e escola, são observadas duas instituições que relacionam o lazer a essas questões (I1 e I6). 
Analisando estes resultados, pode notar que apenas três instituições (I1, I3 e I6) abordam quatro maneiras de se trabalhar o lazer com os estudantes de educação física. As demais (I2 e I4) abordam somente duas temáticas. Além disso, não há menção ao lazer relacionado à escola; isso ocorre apenas na I6. Na maioria das instituições pesquisadas não parece haver nem mesmo uma diferenciação entre a abordagem do lazer para alunos da licenciatura e do bacharelado, o que, em nosso entendimento, deveria existir, pois ao concordar com Barros (1995) a licenciatura e o bacharelado são dois cursos distintos, que preparam profissionais com perfis diferentes com possibilidade de complementação de estudos. Somente a I6 faz esta distinção.

Desta maneira, acreditamos que o currículo deve ser organizado a partir das competências esperadas de cada profissional. $\mathrm{O}$ licenciado que atua na educação formal deve estar apto a elaborar programas adequados aos seus alunos, bem como ter conhecimento sobre a criança e o jovem, já que seu público de atuação é composto majoritariamente por eles. $\mathrm{O}$ bacharel deve poder atuar nos campos da recreação, lazer, esporte de alto rendimento, exercício e saúde, educação física adaptada, entre outros, além de estar apto a elaborar programas de atividades para sua clientela (BARROS, 1995).

Além de observar nos projetos a menção da palavra "lazer", procuramos analisá-los como um todo, percebendo que, mesmo não encontrando em todos os projetos a palavra "lazer", este pode ser trabalhado indiretamente em outras disciplinas. Desta forma, o lazer demonstra sua abrangência e interdisciplinaridade, mencionadas no primeiro capítulo desta dissertação. 
Figura 1 - O Lazer é citado no projeto pedagógico

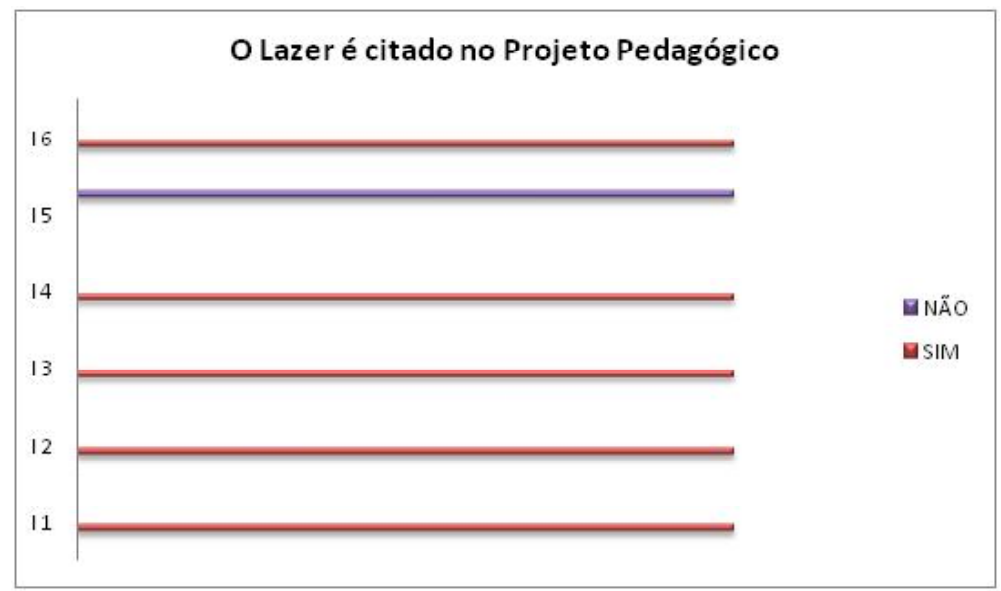

Fonte: FILIPPIS, 2012, p. 58.

Figura 2 - Como o lazer é citado nos projetos pedagógicos.

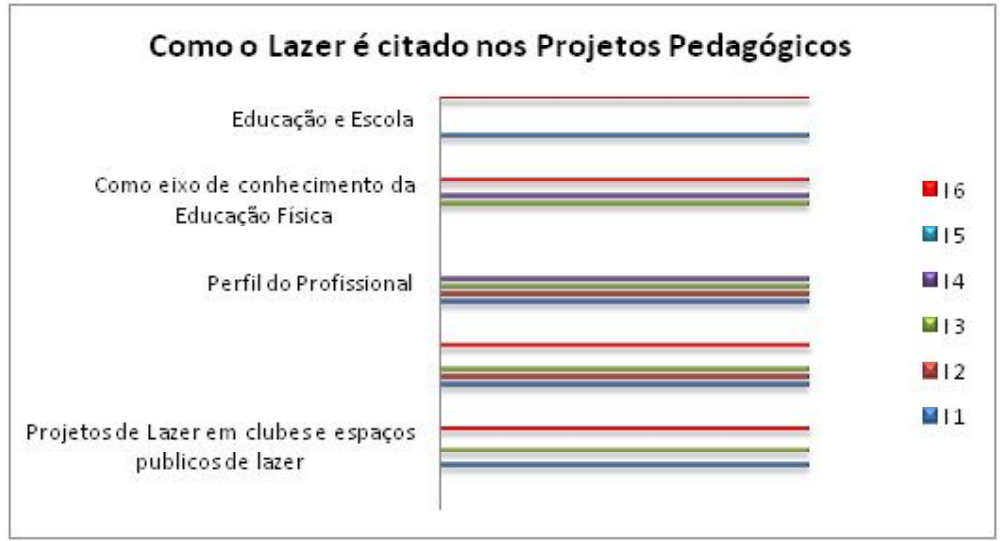

Fonte: FILIPPIS, 2012, p..59.

2.2 DISCIPLINAS DIRETAMENTE VINCULADAS AOS ESTUDOS DO LAZER

Dentre as instituições pesquisadas, apenas uma (I4) apresenta quatro disciplinas diferentes sobre lazer, sendo elas "Estudos do lazer", "Lazer e sociedade", "Lazer e planejamento" e "Fundamentos do lazer". 
A disciplina "Estudos do lazer" dá-se como uma introdução aos estudos do lazer compreendido como fenômeno e direito social, no campo de atuação multidisciplinar. Aborda as relações concretas do lazer na sociedade, especialmente com a Educação Física, considerando as várias fases da vida, bem como as manifestações do lúdico no lazer, na cultura e no planejamento da ação neste campo. Notamos que se trata de uma disciplina teórica e que explica o que é o lazer em seus campos de atuação, além de suas manifestações e relações com outras esferas, como a educação física e o lúdico.

Por sua vez, a disciplina "Lazer e sociedade" compreende o estudo das relações entre esses dois elementos e suas implicações contemporâneas. Observamos que se trata de uma disciplina teórica, complementando a primeira.

A terceira disciplina oferecida nesta instituição, "Lazer e planejamento", aborda questões como compreensão dos elementos técnicos para o planejamento do trabalho do profissional de educação física considerando o conhecimento dos fundamentos teóricos e o campo do lazer. Finalmente, a disciplina "Fundamentos do lazer" traz reflexões sobre o fenômeno do lazer em suas diversas dimensões, abordando as bases teóricas diferenciadas que abordam o tema.

Em outras duas instituições, encontramos três disciplinas que tratam do lazer. Na instituição 1 temos "Estudos do lazer" (já citada acima); "Práticas de recreação e lazer", explicada como um laboratório de atividades recreativas, com uma abordagem conceitual das relações existentes entre a educação física, a recreação e o lazer; e a disciplina "Políticas públicas dos esportes e lazer", que busca analisar as ações desenvolvidas por órgãos públicos e privados em âmbito nacional e municipal, discutindo o papel do Estado, das instituições e da sociedade civil e propondo estratégias de resolução de problemas por meio da ação, por projetos.

$\mathrm{Na}$ instituição 6, que oferece três disciplinas sobre o tema, encontramos "Políticas de ação no campo do lazer", "Introdução aos estudos do lazer em motricidade humana", que aborda a relação histórica entre esses dois elementos, os conceitos e a situação atual, 
com especial atenção à realidade brasileira, e "Repertório de atividades em recreação e lazer", com uma abordagem crítica e criativa do repertório de atividades de recreação e lazer, permitindo que o aluno desenvolva seu próprio repertório.

Por fim, em duas instituições, apenas uma disciplina sobre lazer é ofertada para os alunos. Na instituição 2 a disciplina "Recreação e lazer" relaciona estes elementos à educação física, encorajando uma reflexão sobre o lazer como direito do cidadão e como atividade cultural, social, política e pedagógica. Apresenta o jogo no contexto da recreação, refletindo sobre suas dimensões teórica e prática, bem como procedimentos metodológicos para aplicação em instituições escolares e não escolares.

Na instituição 3 é ofertada a disciplina "Fundamentos do lazer", já explicada. Assim, vale ressaltar que de todas as instituições analisadas, somente a I5 não apresenta nenhuma disciplina diretamente vinculada ao lazer.

Figura 3 - Disciplinas diretamente vinculadas aos estudos o lazer

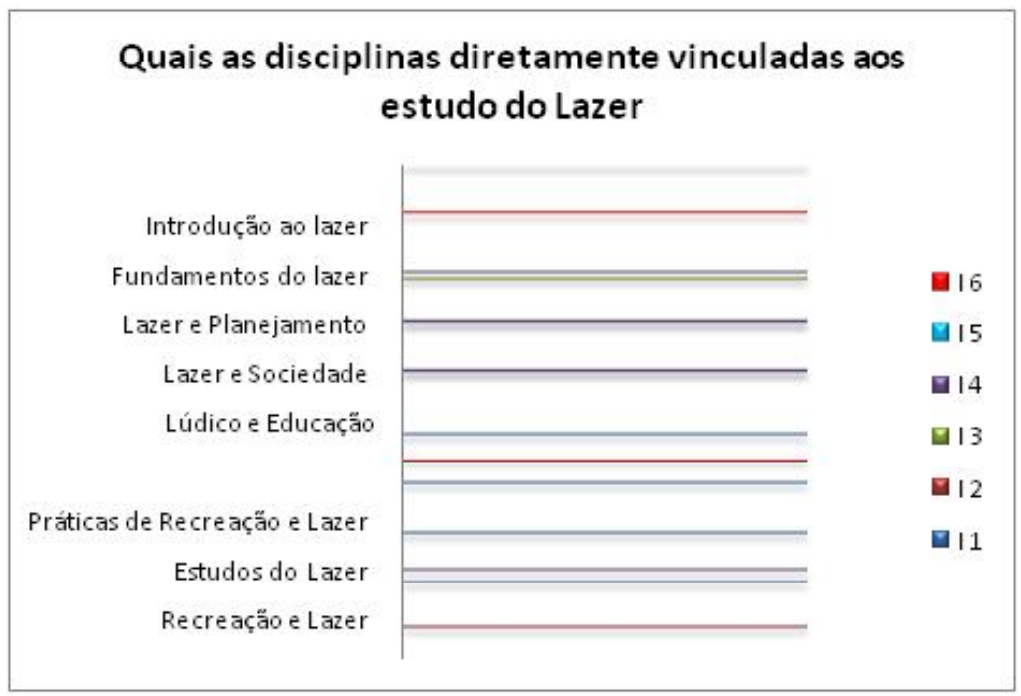

Fonte: FILIPPIS, 2012, p. 61. 


\subsection{VINCULAÇÃO DAS DISCIPLINAS COM OUTRAS ESFERAS DA VIDA}

Para análise deste item foram levados em consideração a definição dos conhecimentos exigidos para a constituição de competências colocadas pelas Diretrizes Curriculares Nacionais para a Formação de Professores da Educação Básica (2012), que deverá, além da formação específica relacionada às diferentes etapas da educação básica, propiciar a inserção no debate contemporâneo mais amplo, envolvendo questões culturais, sociais, econômicas e o conhecimento sobre o desenvolvimento humano, contemplando a cultura geral e profissional; os conhecimentos sobre crianças, adolescentes, jovens e adultos, levando em consideração as especificidades dos alunos com necessidades educacionais especiais; o conhecimento sobre as dimensões cultural, social, política e econômica da educação; e o conhecimento advindo da experiência.

Desta forma, acreditamos que esses conhecimentos possam ser relacionados ao lazer e neste item observarmos a vinculação feita pelas disciplinas específicas da educação física com os acontecimentos do dia a dia vivenciados pelos estudantes.

Todas as instituições pesquisadas fazem a relação de suas disciplinas com a saúde, de modo geral, e com a faixa etária da população com a qual o profissional de educação física atuará.

Outros pontos citados referem-se ao mercado de trabalho (I1, I2, I3, I4 e I6) e à educação (I1, I3, I4, I5 e I6), relacionados por cinco instituições.

Notamos que outra questão abordada nas disciplinas de quatro instituições (I1, I3, I4 e I6) diz respeito a espaços e equipamentos. Consideramos esta discussão de extrema valia, pois é um assunto que engloba a relação do lazer com a educação física, além das políticas públicas.

Outro assunto abordado por quatro instituições (I1, I3, I4 e I6) diz respeito a outras esferas da vida social, como trabalho, família, educação, saúde, religião etc. Nas instituições I3, I4 e I6 as disciplinas também abordam questões de gênero, faixa etária e estereótipos. 
Figura 4 - Vinculação das disciplinas.

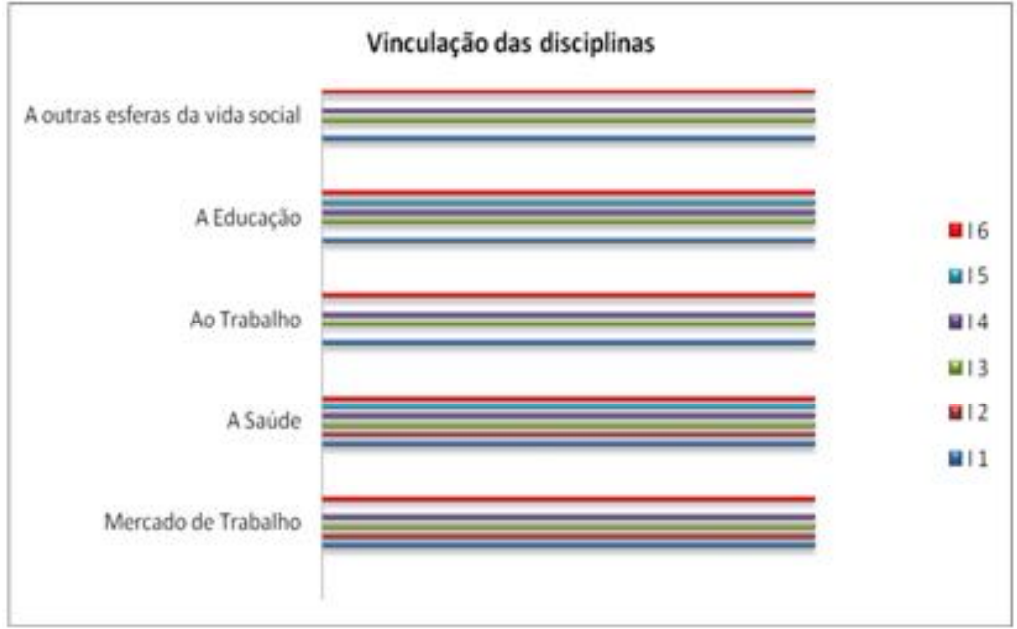

Fonte: FILIPPIS, 2012, p. 62.

Figura 5 - Vinculação das disciplinas.

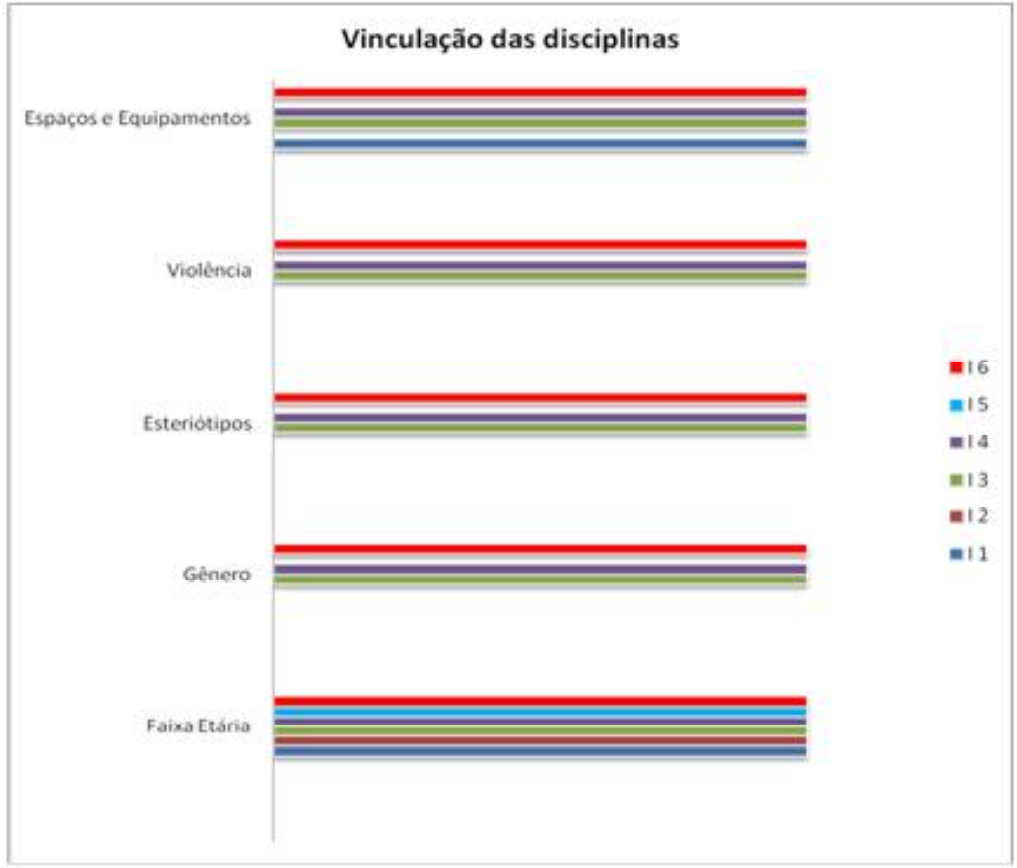

Fonte: FILIPPIS, 2012, p. 63.

Movimento, Porto Alegre, v. 19, n. 03, p. 31-56, jul/set de 2013. 


\subsection{VINCULAÇÃO DAS DISCIPLINAS COM RELAÇÃO AOS CONTEÚDOS CULTURAIS DO LAZER}

Relembrando os conteúdos culturais propostos por Marcellino (2007), baseado em Dumazedier (1980) e Camargo (1986), temos seis áreas fundamentais: (1) o conteúdo manual, que inclui atividades nas quais prevalece a habilidade de manipulação, como jardinagem, artesanato, cuidado com animais; (2) o conteúdo artístico, que abrange as manifestações artísticas, o imaginário; (3) o conteúdo intelectual, que busca o contato com o real, dando ênfase ao conhecimento vivido e experimentado, como a leitura, por exemplo; (4) o conteúdo social, no qual prevalece o contato face a face, um interesse no relacionamento, como frequentar bares, bailes; (5) o conteúdo turístico, caracterizado pela busca da quebra da rotina temporal ou espacial e o contato com novas situações e culturas, como os passeios e viagens; e, finalmente, (6) o conteúdo físico-esportivo, que se caracteriza pelo movimento, abrangendo as práticas esportivas, passeios, pesca, ginástica e todas as atividades em que prevalece o movimento.

Este último conteúdo é considerado especificidade da educação física, em virtude de ter, como principal característica, o movimento. Desta forma, torna-se fundamental que os alunos dos cursos de educação física tenham acesso pelo menos a este conteúdo. Seria importante, também, que os alunos tivessem acesso ao conhecimento dos demais conteúdos para serem capazes de trabalhar no campo do lazer com uma visão abrangente, sabendo que há mais do que esportes e atividades físicas no lazer. Isto, porém, não foi observado nos projetos das instituições: somente a I6 aborda todos os conteúdos culturais do lazer em suas disciplinas.

A instituição 5, que não cita o lazer em seu projeto pedagógico, abrange um único conteúdo do lazer (o físico-esportivo), porém não pelo fato de falar ou não sobre o lazer diretamente, mas por ser um curso de educação física.

Outras três instituições (I1, I2 e I3) abordam os mesmos três conteúdos em suas disciplinas; são eles: o físico-esportivo, o artístico 
e o social. A instituição 4, além desses três conteúdos, aborda, ainda, o turístico. Sendo assim, contempla quatro conteúdos do lazer em suas disciplinas.

Observamos que os conteúdos intelectuais e manuais são excluídos de quase todas as instituições, exceto a I6, que contempla todos os conteúdos.

Assim, nos perguntamos: como pode um profissional de educação física defender a participação da sociedade nos mais variados conteúdos do lazer se nem ele tem acesso a tais informações durante sua formação?

Figura 6 - Vinculação das disciplinas com relação aos conteúdos culturais do lazer.

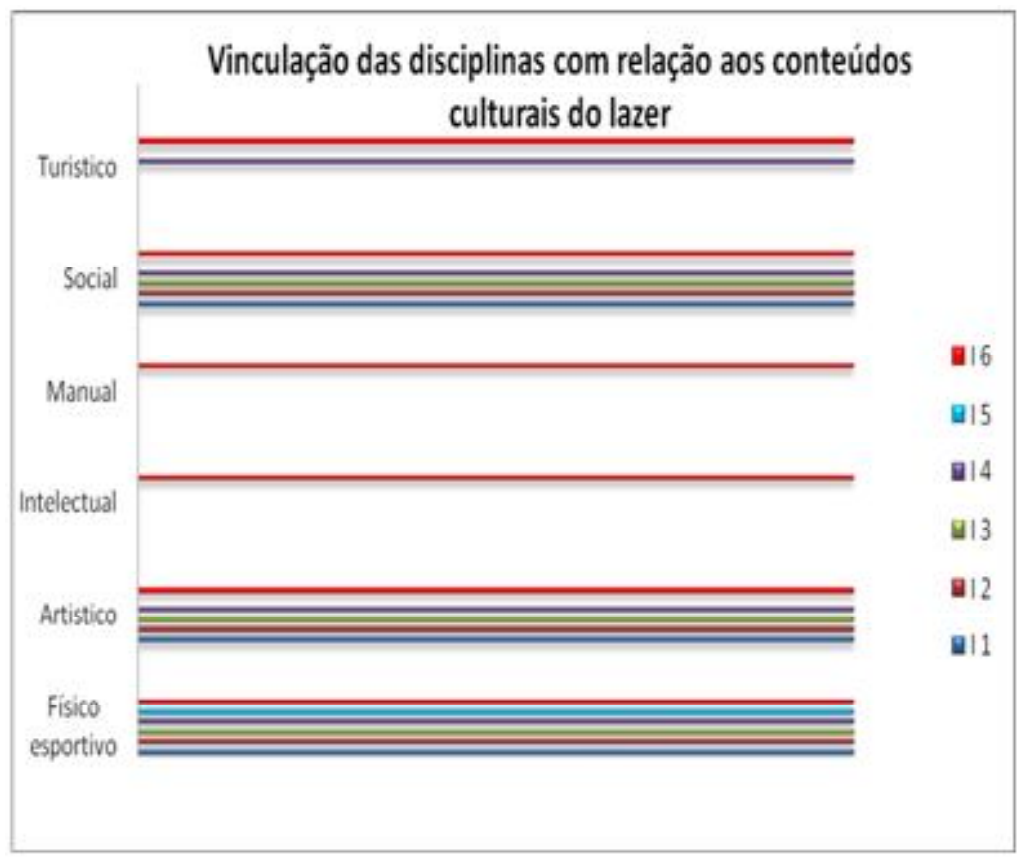

Fonte: FILIPPIS, 2012, p. 65. 
2.5 VINCULAÇÃO DAS DISCIPLINAS COM RELAÇÃO AOS CONTEÚDOS FÍSICOESPORTIVOS

Analisando as disciplinas propostas pelas universidades pesquisadas, apontamos aquelas que dizem respeito ao conteúdo físico-esportivo, sendo que estas, abordando o conteúdo que é específico da educação física, podem ou não relacioná-lo ao lazer.

Observamos a recorrência no que diz respeito aos conteúdos básicos da educação física. Desta forma, as universidades I1, I2, I3, I4 e I6 apresentam em seu projeto pedagógico as disciplinas: Teoria e prática de dança e ritmos; Teoria e prática de esportes, que abrangem o voleibol, handebol, futebol, futsal, basquetebol, ginástica artística e rítmica, natação e lutas. Dentre estas universidades, apenas a I1 não contempla o conteúdo atletismo em seu projeto.

As instituições I1, I2, I4 e I6 apresentam uma disciplina que engloba jogos de raquetes; outra disciplina abordada por quatro instituições (I1, I3, I4 e I6) é "Ginástica geral". "Teoria e prática de jogos e brincadeiras" é disciplina citada em apenas três instituições (I1, I3 e I4). "Esportes de aventura" faz parte dos projetos da I2 e I6. A disciplina "Planejamento e marketing esportivo" consta apenas do projeto pedagógico da I2. E o projeto da I6 traz uma disciplina que trata da organização de eventos escolares e esportivos.

Vemos que todas essas disciplinas dizem respeito à especificidade da educação física e, portanto, podem ser abordadas na perspectiva do lazer. Desta forma, as aulas de voleibol, futebol, dança, natação e as demais citadas, além de colaborarem na formação de um profissional que seja possuidor do conhecimento básico para ser um educador físico, podem auxiliar na formação de um profissional mais completo e competente para atuação na área do lazer.

Para que isso ocorra é necessário que o professor da disciplina inclua em suas aulas, no mínimo, o básico do conhecimento sobre o lazer e suas relações com os conteúdos da educação física, ou seja, como utilizar o conhecimento adquirido em dança, por exemplo, para um projeto de lazer. 
Neste sentido, voltamos a frisar que uma formação qualificada faz-se necessária para uma atuação efetiva junto à sociedade. Assim, para fortalecer nossa opinião, citamos Isayama (2010, p. 13) que diz: a formação deve proporcionar o domínio de conteúdos a serem socializados, por meio do entendimento de seus significados em diferentes contextos e articulações interdisciplinares, e, por fim, o conhecimento de processos de investigação que auxiliem no aperfeiçoamento da ação profissional no campo do lazer.

Desta forma, acreditamos que as instituições citadas acima (I1, I2, I3, I4 e I6) realizem a relação entre as disciplinas consideradas específicas da educação física e as disciplinas contidas no projeto pedagógico, específicas do lazer.

A instituição 5, que não menciona o lazer em seu projeto, também não contempla nenhuma das disciplinas citadas acima. Suas disciplinas vinculadas ao conteúdo físico-esportivo são denominadas: educação física escolar; educação física na educação infantil i e ii; educação física no ensino fundamental i, ii e iii; educação física no ensino médio.

Neste caso, podemos apenas supor que, nesta instituição, as disciplinas específicas da educação física são utilizadas como ferramentas para uma formação que englobe o lazer, uma vez que em sua grade curricular não se encontra nenhuma disciplina que trate dele diretamente.

Isto corrobora as constatações de Isayama (2002), que, ao analisar currículos dos mais variados cursos, como fisioterapia, hotelaria, turismo, artes, administração, entre outros, identifica que as discussões sobre lazer aparecem em estágio inicial, sendo feitas de modo superficial. Isso caracteriza uma incompatibilidade entre o estudo e o campo de atuação que se expande cada dia mais.

Com relação à questão do ensino em suas diferentes vertentes (licenciatura e bacharelado), notamos que ainda temos um grande caminho a percorrer no que diz respeito à formação profissional em educação física e em lazer: buscando melhorias nas propostas 
curriculares das instituições de ensino, procurando englobar o lazer nos cursos de formação e mantendo sua característica multidisciplinar.

Figura 7 - Vinculação das disciplinas com relação aos conteúdos físico-esportivos.

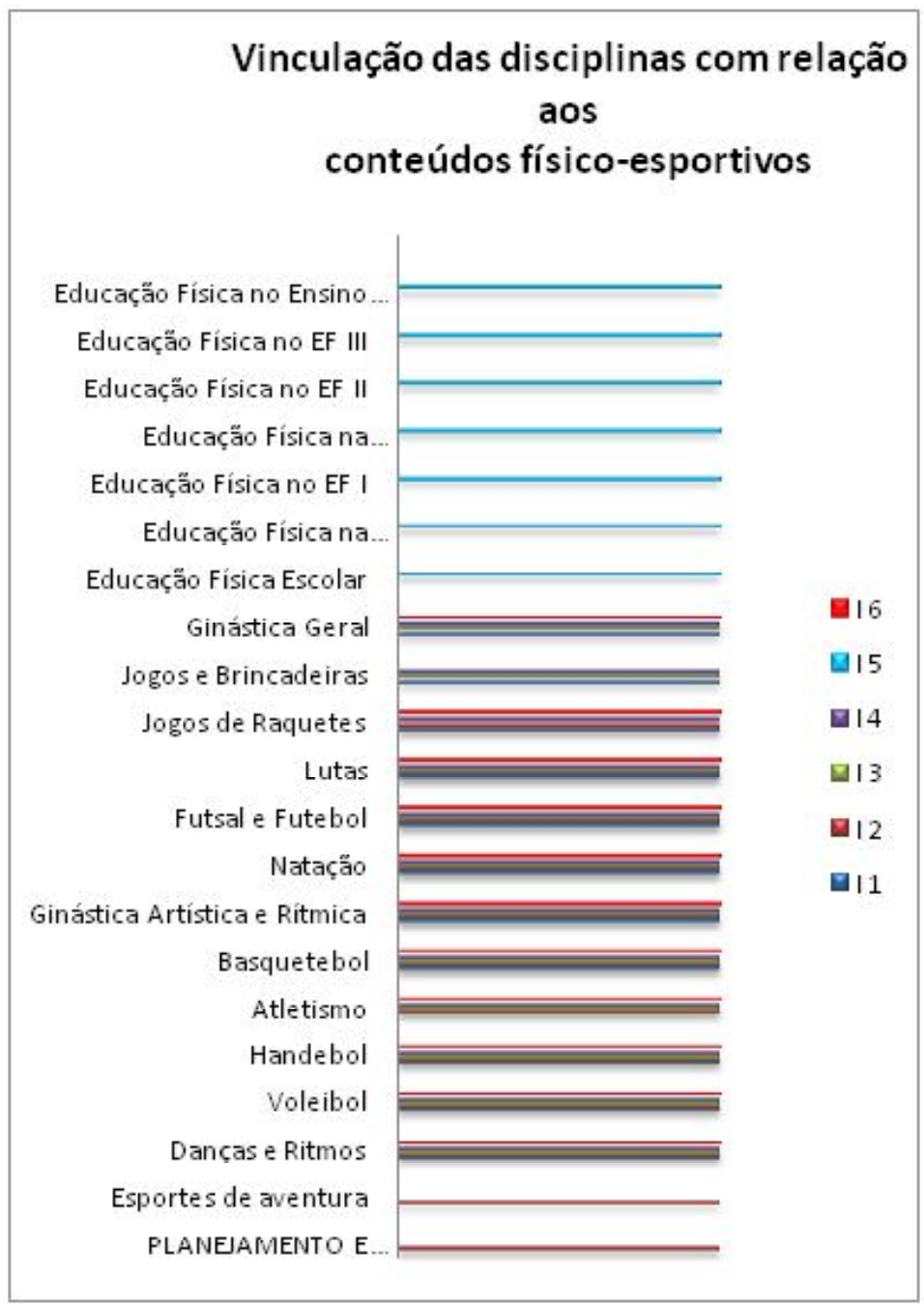

Fonte: FILIPPIS, 2012, p. 68. 
2.6 RELAÇÃO DA BIBLIOGRAFIA BÁSICA UTILIZADA NAS EMENTAS DAS DISCIPLINAS RELACIONADAS AO LAZER: PRINCIPAIS AUTORES

Outro aspecto que analisamos foram as referências bibliográficas utilizadas nas disciplinas relacionadas ao lazer. Nesta questão observamos que nenhuma das instituições pesquisadas usam teses ou dissertações como referência para suas disciplinas.

Este fato provoca certa inquietação, pois conforme enfatizando, defendemos uma formação continuada; para tal, acreditamos ser imprescindível que os graduandos tenham acesso a teses e dissertações. Isso contribuiria para enriquecer o contato dos estudantes para além dos livros.

A formação continuada é encarada como uma possibilidade do profissional sobressair-se perante outros. Assim, esta formação deve ser almejada pelo próprio profissional. Neste sentido, a participação em congressos da área, seminários, palestras, cursos de extensão e cursos de pós-graduação torna-se um diferencial para o mercado de trabalho, que busca sempre um profissional cada vez mais qualificado.

Além disso, a participação em cursos, congressos etc. pode estimular o interesse do profissional em buscar, cada vez mais, ampliar seus conhecimentos sobre determinado assunto ou área. Assim, enfatizamos que o contato com teses e dissertações pode gerar um interesse pela formação continuada.

Observamos que somente duas instituições pesquisadas (I4 e I6) utilizam periódicos como referência básica em suas disciplinas sobre lazer. Isto demonstra maior interesse em proporcionar aos alunos o contato com artigos e periódicos, ampliando suas referências para uma formação continuada.

Dentre as instituições cujo projeto pedagógico analisamos, a única que não apresenta bibliografia sobre lazer é a instituição cinco, já que não o cita em seu projeto. As demais (I1, I2, I3, I4 e I6) utilizam livros em suas referências. 
Além disso, analisamos quais autores são mais utilizados nas disciplinas específicas de lazer. Marcellino é destacado como o autor mais utilizado nas disciplinas diretamente relacionadas ao lazer, sendo citado em todas as instituições pesquisadas nas quais o lazer é mencionado nos projetos pedagógicos; encontramos 12 obras do autor relacionadas nos planos de ensino. Bruhns aparece como um das autoras mais utilizadas (I1, I2, I3 e I4).

Outros autores importantes para a área do lazer são citados nas referências dos projetos. São eles: Luis Octávio de Lima Camargo, Joffre Dumazedier, Leila Mirtes dos Santos Magalhães Pinto, Gisele Schwartz e João Batista Freire. Este último é utilizado, inclusive, na instituição cinco, que mesmo não ofertando nenhuma disciplina específica sobre lazer, utiliza-o em suas disciplinas específicas da área da educação física, onde o lazer pode, também, ser abordado.

Figura 8 - Relação da bibliografia básica utilizada nas ementas das disciplinas relacionadas ao lazer: principais autores.

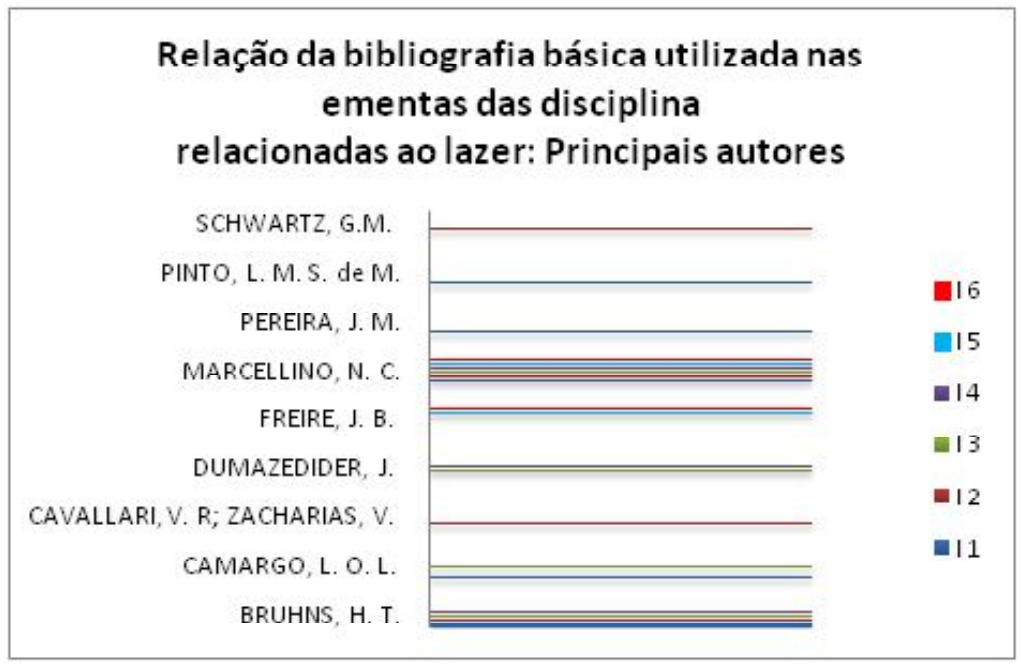

Fonte: FILIPPIS, 2012, p. 70. 
Figura 9 - Relação da bibliografia básica utilizada nas ementas das disciplinas relacionadas ao lazer

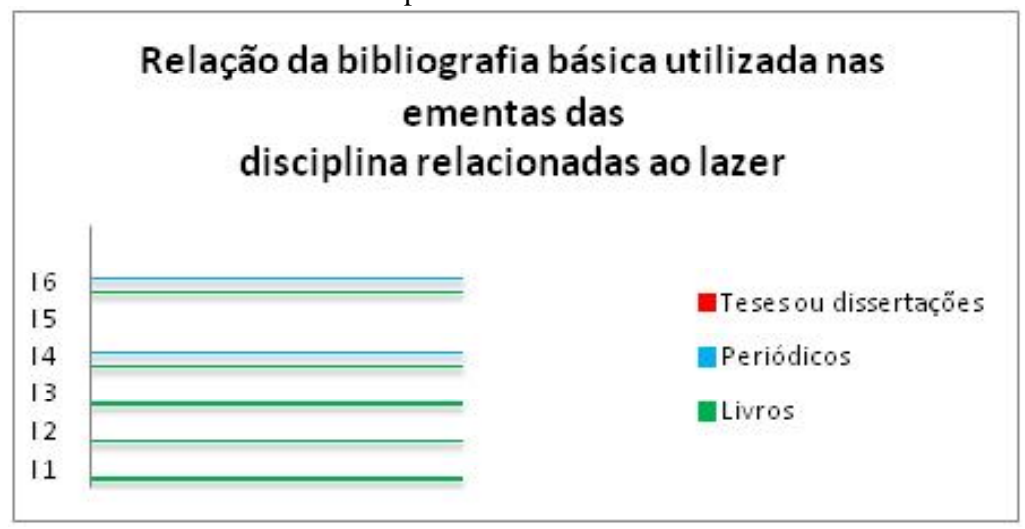

Fonte: FILIPPIS, 2012, p. 70.

\subsection{RELAÇÃo ENTRE TEORIA E PRÁTICA}

Ressaltamos, a divisão das aulas em teoria e prática. Pensamos ser válida esta observação, pois, como dito anteriormente, defendemos que uma formação completa depende de um equilíbrio entre aulas práticas e teóricas.

Assim, retomando nossa discussão, concordamos com Isayama que se o profissional é possuidor de um referencial teórico sólido, compreenderá sua prática por meio de novos olhares. Esta formação possibilitaria a socialização dos conteúdos por meio do entendimento do seu significado. Finaliza o autor dizendo que a formação na área do lazer "deve ser pautada na competência técnica, científica, política, filosófica e pedagógica e no conhecimento crítico da realidade" (2010, p. 13).

Para analisar a quantidade de aulas teóricas e práticas, observamos, em primeiro lugar, se havia diferença na carga horária dos cursos de licenciatura e bacharelado. Das seis instituições pesquisadas, metade possui carga horária igual para os dois cursos (I3, I4 e I5), sendo 420 horas/aulas práticas e 2.430 horas teóricas na I3; 800 horas práticas e 2 mil horas teóricas na I4; e 1.050 horas práticas e 2.595 horas teóricas na I5. 
Nas outras três instituições há diferença entre a carga horária dos cursos destinados à teoria e à prática. Assim, na I1, o curso de bacharelado possui 860 horas práticas e 1.780 horas teóricas; e o curso de licenciatura conta com 366 horas práticas e 1.434 horas teóricas.

A I2 destina ao curso de bacharelado 640 horas práticas e 1.420 horas teóricas; para os licenciados são 480 horas práticas e 960 horas teóricas. A última instituição que diferencia a quantidade de aulas para os cursos é a de número seis, onde, para o bacharelado são 1.326 horas práticas e 1.908 horas teóricas e para a licenciatura são 1.377 horas práticas e 1.683 horas teóricas.

Todas as instituições pesquisadas possuem uma carga horária que contempla aulas teóricas e práticas, o que corrobora os estudos desenvolvidos sobre esta questão.

Figura 10 - Quantidade de horas/aulas: licenciatura e bacharelado3

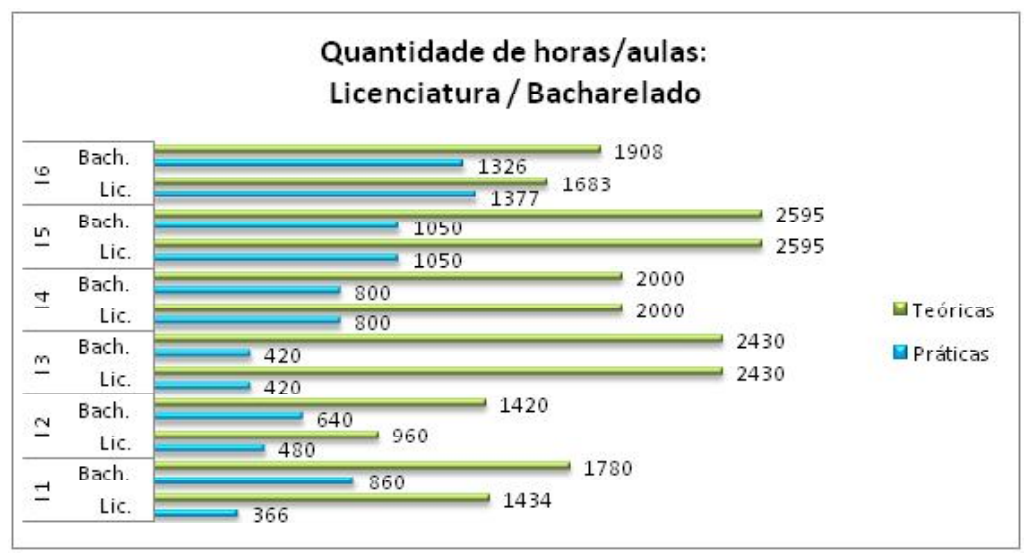

Fonte: FILIPPIS, 2012, p. 72. 


\section{Considerações FinaIS}

Pelo estudo realizado, analisamos a importância de refletir sobre a formação profissional em geral, bem como a formação em educação física relacionada ao lazer.

Nossa pesquisa conclui que há relação entre a formação profissional em lazer nos cursos superiores de Educação Física e a atuação em campo; que os cursos de Educação Física são espaços para a formação profissional na área, porém deve ser abordada em outros cursos pela necessidade de, pela formação, contemplar o caráter pluri e multiprofissional em busca de trabalhos interdisciplinares, inerentes à transversalidade do objeto de estudo o lazer.

Isto nos leva a outra preocupação no que diz respeito às disciplinas sobre lazer e educação física: a dicotomia entre prática e teoria. Durante a pesquisa entendemos que tanto a teoria quanto a prática são igualmente necessárias e uma não deve se sobressair à outra. O profissional, além do conhecimento prático, deve ter um sólido conhecimento teórico para que sua futura prática seja intencional, crítica e criativa, possibilitando a manifestação do lazer em seu todo.

Outros aspectos foram avaliados além das categorias de análise, e atentamos para a questão da diferenciação entre os cursos de bacharelado e licenciatura em Educação Física, nos quais acreditamos existir uma diferença de abordagem em relação aos conteúdos específicos da educação física e do lazer, pelo simples fato de serem dois campos distintos de atuação. Porém, apesar da atuação do profissional de educação física ser diferente na licenciatura e no bacharelado e algumas instituições possuírem planos de ensino diferentes, dando ênfase ao campo de atuação no qual o aluno está sendo formado, essas disciplinas diretamente vinculadas ao lazer são eliminadas caso o aluno opte pelas duas formações, dando a característica de disciplina básica para as duas formações, deixando de lado a importância na diferença da formação do licenciado e do bacharel. 
Nesta questão, devemos ressaltar a relevância em estudar, pesquisar e melhorar as grades curriculares dos cursos de Educação Física para uma formação mais promissora no que concerne ao lazer.

Ressaltamos que somente as instituições dois e seis explicitaram com o cronograma de aula da disciplina. Além disso, alguns projetos pedagógicos foram apresentados sem suas alterações, mostrandose desatualizados, dificultando a análise.

Nesta questão, apenas um professor da instituição (I6) possui planos de ensino diferenciados para licenciatura e bacharelado para as disciplinas diretamente vinculadas ao lazer. Isto demonstra preocupação com a formação do aluno, pois deve existir uma diferença de abordagem em relação aos conteúdos específicos da educação física e do lazer pelo simples fato de serem dois campos distintos de atuação.

Complementando a formação do aluno, tanto da graduação como da pós-graduação, temos os grupos de pesquisa. Dentre as instituições pesquisadas, I3, I4 e I6 possuem grupos de pesquisa de lazer, lembrando que a I3 possui apenas uma disciplina diretamente relacionada ao lazer.

Portanto, isso pode significar um ideal de formação, por meio da reelaboração e/ou reorganização dos currículos, tendo como meta uma melhor relação entre a formação e a intervenção profissional, ansiando pela capacidade de criatividade do indivíduo, buscando mudanças da realidade.

Desta forma, entendemos as instituições de ensino como um espaço de formação do homem e da sociedade, buscando saberes mais complexos, reflexivos e críticos que gerem questionamentos, não só sobre nossa área, mas a vida em sociedade em geral.

Encontramos no lazer uma possibilidade de transformação dos sujeitos, de incentivo à criticidade e criatividade em todas as esferas da vida, como trabalho, família, religião e política, além de ser um momento de novas oportunidades em relação à cultura, tanto no conhecimento, quanto na sua produção. 
O lazer, compreendido em sua amplitude, articula-se aos campos de atuação da Educação Física, pois, desde seu surgimento, o profissional dessa área desenvolve atividades e trabalhos dentro e fora de nosso país (BRAMANTE, 2005).

Somente após 1962, no entanto, por meio do Parecer n. 298, a disciplina "Recreação e lazer" foi inserida oficialmente nos currículos de formação em Educação Física (PINTO, 2001). A pesquisa sobre lazer nas faculdades de Educação Física começa a ser sistematizada somente a partir de 1980 (MARCELLINO, 1995).

Dessa forma, existe uma diferença temporal significativa entre ação profissional, ensino e pesquisa na área (MARCELLINO, 2012).

Comparando a dados coletados em pesquisa anterior (ISAYAMA, 2002), o número de disciplinas diretamente ligadas aos estudos do lazer está aumentando nos cursos de Educação Física, e onde existem, não se reduzem à recreação, contemplando as relações com as outras esferas da vida, historicidade e abrangendo os diferentes conteúdos culturais, antes restritos aos fisicoeportivos.

Assim, talvez agora, no estado de São Paulo, começamos a colher os frutos das pesquisas realizadas a partir da década de 1980, conforme citado acima.

Este estudo procura colaborar com a formação profissional em lazer nos cursos de Educação Física e esperamos que dele resultem mais discussões sobre o tema, gerando questionamentos e mudanças nos projetos pedagógicos, procurando somar na formação de profissionais comprometidos, éticos e, sobretudo, criativos em sua atuação. 


\section{Professional training in leisure in Physical} Education courses, in the State of São Paulo

Abstract: This study aims to investigate the relationship between vocational training in leisure within the Physical Education courses and the labor market in this area in the attempt to see if there are differences in the undergraduate courses and how they have been training for a professional performance in the area. The literature review and desk research were made through content analysis. The results highlight that the number of subjects is increasing; they are not reduced to recreation, but contemplate relations with other spheres of life, historicity and cover different cultural contents

Keywords: Professional training. Physical Education. Leisure Activities.

\section{Cursos de formación en ocio libre en la} Educación Física en el Estado de São Paulo

Resumen: Este estudio tiene como objetivo investigar las relaciones entre la formación profesional en el ocio en los cursos de Educación Física y el mercado de trabajo en esta área, tratando de identificar si existen diferencias en la formación de la licenciatura y de posgrado y cómo los cursos han estado trabajando la formación profesional para el desempeño profesional en esta área. Se realizaron análisis de contenido bibliográfico y documental. Los resultados revelan que el número de disciplinas va aumentando, no se reduciendo a la recreación, pero contemplando las relaciones con otras esferas de la vida, la historicidad y cubriendo los diferentes contenidos culturales.

Palabras clave: Formación Profesional. Educación Física. Actividades de ocio.

\section{REFERÊNCIAS}

BARROS, J. M. C. Educação Física na Unesp de Rio Claro: bacharelado e licenciatura. Motriz, Rio Claro, v. 1, n. 1, p. 71-80, jun. 1995.

BRAMANTE, A. C. Recreação e lazer: o futuro em nossas mãos. In: MOREIRA, W. W. (Org.). Educação física e esportes: perspectivas para o século XXI. 12. ed. Campinas: Papirus, 2005.

BRASIL. Ministério da Educação e Cultura. Disponível em: <www.inep. gov.br/ pesquisa>. Acesso em: 30 jul. 2012. 
BRUYNE, P. de. Dinâmica da pesquisa em ciências sociais. Rio de Janeiro: Francisco Alves, 1991.

CAMARGO, L. O. de L. O que é lazer. S.Paulo, Brasiliense, 1986.

DIRETRIZES currículares nacionais. Disponível em: <http://portal.mec.gov.br/ index.php?option=com_content\&view=article\&id=12991\&ltemid=866> Acesso em: 3 dez. 2012.

DUMAZEDIER, J. Questionamento teórico do lazer. Centro de estudos e recreação - CELAR. Porto Alegre: Pontifícia Universidade Católica do Rio Grande do Sul, 1975.

FILIPPIS, A, D. Formação profissional em lazer, nos cursos de Educação Física, no estado de São Paulo. Piracicaba-SP, 2012.

GIL, A. C. Como elaborar projetos de pesquisa. 4. ed. São Paulo: Atlas, 2002.

ISAYAMA, H. F. Formação profissional no âmbito do lazer: desafios e perspectivas. In: ISAYAMA, H. F. (Org.). Lazer em estudo: currículo e formação profissional. Campinas: Papirus, 2010.

. Recreação e lazer como integrantes dos currículos dos cursos de graduação em Educação Física. Tese (Doutorado em Educação Física) Universidade de Campinas, Campinas, SP, 2002.

LOMBARDI, M. I. Lazer como prática educativa: as possibilidades para o desenvolvimento humano. Dissertação (Mestrado em Educação Física) - Faculdade de Educação Física da Universidade Estadual de Campinas, Campinas, SP, 2005.

MARCELLINO, N. C. A dicotomia teoria/prática na Educação Física. Motrivivência, Florianópolis, v. 7, n. 8, p. 73-78, 1995.

Lazer e educação. 2. ed. Campinas: Papirus, 1990.

Lazer e humanização. 7. ed. Campinas: Papirus, 2003.

. Lazer e cultura: algumas aproximações. In: MARCELLINO, N. C. (Org.). Lazer e cultura. Campinas: Alínea, 2007.

. Os estudos do lazer e algumas escolas antropológicas. In: COLÓQUIO EDUCAÇÃO FÍSICAE CIÊNCIAS SOCIAIS EM DIÁLOGO:AS PRÁTICAS CORPORAIS COMO MANIFESTAÇÃO CULTURAL E DE LAZER NA CONTEMPORANEIDADE., 2. 2012. Anais... Piracicaba: Universidade Metodista de Piracicaba, 2012. p. 16-23, n. 1.

PINTO, L. M. S. M. Formação de educadores e educadoras para o lazer: saberes e competências. Revista Brasileira de Ciências do Esporte, v. 22, n. 3, p. 53-71, mai. 2001. 
56 ArtigosOriginais André De Filippis, Nelson C. Marcellino

Lazer e educação: desafios da atualidade. In: MARCELLINO, N. C. (Org.). Lazer e sociedade: múltiplas relações. Campinas: Alínea, 2008.

REQUIXA, R. Sugestões de diretrizes para uma política nacional de lazer. São Paulo: Sesc, 1980.

SEVERINO, A. J. Metodologia do trabalho científico. 19. ed. São Paulo: Cortez, 2002.

WERNECK, C. L. G. Lazer, recreação e educação física. Belo Horizonte: Autêntica, 2003.

Endereço para correspondência:

André De Filippis

Avenida Celso Garcia, 1907 Ap.163 BI.20

CEP:03015-000 - Brás

São Paulo - SP

Recebido em: 05.03.2013

Aprovado em: 08.04.2013 